\title{
Evaluating antimicrobial appropriateness in a tertiary care pediatric ICU in Saudi Arabia: a retrospective cohort study
}

\author{
Yasser M. Kazzaz ${ }^{1,2,3^{*}} \mathbb{0}$, Haneen AlTurki ${ }^{1,3}$, Lama Aleisa ${ }^{1,3}$, Bashaer Alahmadi ${ }^{1,3}$, Nora Alfattoh ${ }^{1,3}$ \\ and Nadia Alattas ${ }^{1,2}$
}

\begin{abstract}
Background: Inappropriate antibiotic utilization is associated with the emergence of antimicrobial resistance (AMR) and a decline in antibiotic susceptibility in many pathogenic organisms isolated in intensive care units. Antibiotic stewardship programs (ASPs) have been recommended as a strategy to reduce and delay the impact of AMR. A crucial step in ASPs is understanding antibiotic utilization practices and quantifying the problem of inappropriate antibiotic use to support a targeted solution. We aim to characterize antibiotic utilization and determine the appropriateness of antibiotic prescription in a tertiary care pediatric intensive care unit.

Methods: A retrospective cohort study was conducted at King Abdullah Specialized Children's Hospital, Riyadh, Saudi Arabia, over a 6-month period. Days of therapy (DOT) and DOT per 1000 patient-days were used as measures of antibiotic consumption. The appropriateness of antibiotic use was assessed by two independent pediatric infectious disease physicians based on the Centers for Disease Control and Prevention 12-step Campaign to prevent antimicrobial resistance among hospitalized children.

Results: During the study period, 497 patients were admitted to the PICU, accounting for 3009 patient-days. A total of 274 antibiotic courses were administered over 2553 antibiotic days. Forty-eight percent of antibiotic courses were found to be nonadherent to at least 1 CDC step. The top reasons were inappropriate antibiotic choice (empirical or definitive) and inappropriate prophylaxis durations. Cefazolin and vancomycin contributed to the highest percentage of inappropriate DOTs.

Conclusions: Antibiotic consumption was high with significant inappropriate utilization. These data could inform decision-making in antimicrobial stewardship programs and strategies. The CDC steps provide a more objective tool and limit biases when assessing antibiotic appropriateness
\end{abstract}

Keywords: Saudi Arabia, Children, Days of therapy, Antibiotics, Antimicrobial stewardship, Antimicrobial resistance

\section{Background}

Antibiotics are the most common medications prescribed in pediatric intensive care units (PICUs), with up to $50-100 \%$ of patients receiving an antibiotic

*Correspondence: kazzazy@ngha.med.sa

${ }^{1}$ Department of Pediatrics, Ministry of National Guards - Health Affairs, Riyadh, Kingdom of Saudi Arabia

Full list of author information is available at the end of the article prescription [1-5]. Patients in a PICU setting have a high prevalence of community and hospital-acquired infections and an overall high risk of morbidity and mortality [6-8]. However, antibiotics are not justified in every case and their prescription may signify a lack of judicious use or improper reasoning. It has been found that almost $20-50 \%$ of all antibiotics prescribed in a pediatric critical care setting are inappropriate [2, 9]. Such inappropriate antibiotic utilization contributes to emergence of original author(s) and the source, provide a link to the Creative Commons licence, and indicate if changes were made. The images or other third party material in this article are included in the article's Creative Commons licence, unless indicated otherwise in a credit line to the material. If material is not included in the article's Creative Commons licence and your intended use is not permitted by statutory regulation or exceeds the permitted use, you will need to obtain permission directly from the copyright holder. To view a copy of this licence, visit http://creativecommons.org/licenses/by/4.0/. The Creative Commons Public Domain Dedication waiver (http://creativeco mmons.org/publicdomain/zero/1.0/) applies to the data made available in this article, unless otherwise stated in a credit line to the data. 
antimicrobial resistance (AMR), adverse drug reactions, and additional morbidity and hospitalization costs [1012]. It has been estimated that AMR will result in 10 million deaths by 2050 if no global action is taken [13]. In 2015, the World Health Organization (WHO) introduced a global strategy to address AMR that incorporated several interventions, including the reduction of inappropriate antimicrobial utilization [14, 15]. With increasing reports of emerging AMR and declining pathogen susceptibility in ICU patients, Saudi Arabia joined the WHO global action plan for Containment of Antimicrobial Resistance [16-18].

Antimicrobial stewardship programs (ASPs) are recommended to decrease inappropriate antibiotic use and mitigate its effects $[19,20]$. This requires an understanding of current antibiotic prescription practices and rationale. Data on antibiotic prescription in our institute have been published without detailing indications, types of infections or the appropriateness of antibiotic prescriptions [21]. Such information helps to quantify the problem and identify the main areas that require attention and modification through an ASP strategy. The objectives of this study were to characterize antibiotic utilization, determine the appropriateness of antibiotic use by applying the Center for Disease Control and Prevention (CDC) 12-step Strategy to prevent antimicrobial resistance among hospitalized children, and study factors associated with inappropriate antibiotic prescription in a tertiary care PICU.

\section{Methods}

\section{Setting}

This retrospective cohort study was conducted at King Abdullah Specialized Children's Hospital (KASCH), an academic tertiary center in Riyadh, Saudi Arabia with a current capacity of 220 beds. The hospital has a 25-bed closed medical and surgical PICU admitting approximately 1000 patients per year. At the time of this study, there were no approved local antimicrobial guidelines, and no antibiotic stewardship program or strategies were implemented.

\section{Study design}

A retrospective cohort study was conducted from January to June 2017 (6 months). The Institutional Review Board (IRB) at King Abdullah International Medical Research Center (KAIMRC) approved the study, and the requirement for informed consent was waived.

\section{Population}

All pediatric patients aged $0-14$ years who were admitted to the PICU and started on antibiotics during the study period were included. Patients were excluded from the study if they were $>14$ years of age, or were known to have an immunocompromising condition (including all post-transplant patients and oncological patients within 6 months of receiving chemotherapy), or on immunecompromising medications, or only requiring antifungal or antiviral agents.

\section{Data collection}

Data from electronic medical records were collected using a standardized form and reviewed by two pediatric infectious disease physicians in the study group. Data collected included patient demographics, disease comorbidities, admitting and/or infectious diagnoses, admission type (medical, surgical, trauma, burn), indication for antibiotics, documentation of antibiotic indication in medical chart, microbiological results on documented infections, consultation of infectious disease (ID) services, and antibiotic utilization (type and duration). Identified infections were reviewed, and multidrugresistant organisms (MDROs) were identified based on susceptibility patterns and resistance to most available antibiotics.

Antibiotic indications were classified as empiric (based on clinical suspicion of infection or positive culture with pending susceptibility), definitive (treating an identified pathogen with known antimicrobial susceptibility), or prophylactic (mainly perioperatively, to prevent infection in a patient at risk) [22, 23]. For empiric antibiotics, decisions about antibiotics after $72 \mathrm{~h}$ was classified as follows: antibiotics were stopped (i.e., infection ruled out), antibiotics were continued with a planned duration, antibiotics were changed as per microbial culture results and clinical condition (i.e., de-escalation to definitive treatment), or no action was taken (i.e., no decision or plan was documented and the same antibiotics were continued).

\section{Outcome definitions}

The appropriateness of antibiotic use was independently assessed by two pediatric ID physicians. Consensus agreement was sought in more complex cases and when opinions differed. Appropriateness was based on clinical judgment and classified using the CDC 12-step Campaign to prevent antimicrobial resistance among hospitalized children [24]. The CDC 12-step protocol covers four main domains: preventing infection, effectively diagnosing and treating infection, using antimicrobials wisely, and preventing transmission. Adherence to 5 of the 12 steps relating to the appropriateness of antibiotics was utilized in the study. These steps were targeting the pathogen (step 4), practicing antimicrobial control (step 6), treating infection and not contamination or colonization (step 8), knowing when to say no to antibiotics (step 9) and stopping antibiotics if infection was treated 
or ruled out (step 10). These steps were elaborated on with some examples to improve clarity and unify understanding of each step for the evaluators (Table 1). Additionally, step 5, accessing the experts (i.e., consulting the ID service), was also evaluated separately.

Days of therapy (DOT) per 1000 patient-days was used to quantify antibiotic consumption. DOT was defined as the number of days that a patient received antibiotics regardless of the dose. When a patient received more than one antibiotic simultaneously, one DOT was counted for every antibiotic given [25]. Patient days were defined as the number of days that all patients were at risk for antimicrobial exposure [26]. Only antibiotics received during the PICU stay were calculated. Any courses prior to or after the PICU stay were not included in data collection or assessed for appropriateness.

\section{Statistical methods}

IBM SPSS version 26 was used to analyze the data. The median and percentile (25th-75th) were used to describe quantitative variables, such as age and duration of antibiotic courses. Frequencies and percentages were used to describe qualitative variables, such as gender, admission type, and indication for antibiotics. Comparisons between appropriate and inappropriate antibiotic courses were performed using Fisher's exact test for categorical data and Mann-Whitney $U$ test for continuous data. A P-value $<0.05$ was considered statistically significant for all analyses.

\section{Results}

During the study period, 497 patients were admitted to the PICU, accounting for 3009 patient days. After excluding 238 patients based on the study criteria, 259 patients were included in the review. Table 2 shows the characteristics of patients in the cohort. One hundred thirty-two (50.8\%) patients were male, and the median age was 22 months (IQR: 5-65 months).

Overall, 259 children received 274 antibiotic courses, resulting in 2553 DOTs. The median duration of an antibiotic course was 8 days (IQR, 5-13). The reason for antibiotic initiation was empiric in 187 courses (68.2\%), prophylactic in 61 courses $(22.3 \%)$, and definitive in 26 courses $(9.5 \%)$. The most common clinical indications for antibiotic initiation were communityacquired pneumonia (19.3\%), hospital-acquired sepsis $(10.6 \%)$, community-acquired sepsis $(9.9 \%)$ and bronchiolitis (9.5\%).

Compared to appropriate antibiotic courses, inappropriate courses were more likely in surgical admissions and in patients receiving antibiotics prophylactically $(\mathrm{P}<0.05)$. A higher proportion of inappropriate courses occurred in patients receiving antibiotics post CNS procedures $(P=0.001)$. The duration of antibiotic courses was significantly higher in children with inappropriate antibiotic use than in children who had appropriate antibiotic use (median of 10 vs. 7.0, $\mathrm{P} \leq 0.001$ ). For empiric antibiotics, no action taken at $72 \mathrm{~h}$ was associated with a higher percentage of inappropriate antibiotic courses, $20.8 \%$ versus $9.1 \%(P=0.031)$.

Table 3 shows the distribution of nonadherent courses based on the CDC steps violated. Out of 274 courses, 133 $(48.5 \%)$ were found to be nonadherent to at least 1 of the five CDC steps. Step 6 (Practice antimicrobial control) was the most prevalent step violated, followed by step 4 (Target the pathogen).

Figure 1 lists the ten most frequently consumed antibiotics in the PICU and the number of inappropriate DOT per antibiotic. In our center, third generation cephalosporins, vancomycin, and cefazolin were the most frequently used antibiotics. Cefazolin and vancomycin, were the most inappropriately used antibiotic therapies.

Table 1 Definitions and clarification of selected CDC 12-step recommendations

\begin{tabular}{|c|c|}
\hline CDC Step & Clarification \\
\hline Step 4: Target the pathogen & $\begin{array}{l}\text { Inappropriate empiric antibiotic choice based on the likely pathogen } \\
\text { Inappropriate definitive antibiotic choice based on identified pathogen susceptibility (need } \\
\text { for de-escalation) }\end{array}$ \\
\hline Step 6: Practice antimicrobial control & $\begin{array}{l}\text { Inappropriate prophylaxis regimen (drug or duration) } \\
\text { Inappropriate antibiotic combination (redundant coverage) } \\
\text { Inappropriate route of administration (requiring a shift from intravenous administration to } \\
\text { oral) } \\
\text { Inappropriate dose of antibiotic (based on indication, renal function, etc.) (not assessed in this } \\
\text { study) }\end{array}$ \\
\hline Step 8: Treat infection, not contamination or colonization & Treating contamination or colonization and not a true, lab-confirmed confirmed infection \\
\hline Step 9: Know when to say 'no' & $\begin{array}{l}\text { Starting empirical vancomycin or broad-spectrum antibiotics (e.g. meropenem, piperacillin/ } \\
\text { tazobactam, or ceftazidime) unnecessarily }\end{array}$ \\
\hline Step 10: Stop infection when cured or unlikely & $\begin{array}{l}\text { Continuing antibiotics despite ruling out infection or having negative cultures or complet- } \\
\text { ing an appropriate duration of therapy }\end{array}$ \\
\hline
\end{tabular}


Table 2 Characteristics of the study cohort

\begin{tabular}{|c|c|c|c|c|c|c|c|}
\hline \multirow[t]{2}{*}{ Variable } & \multicolumn{2}{|c|}{ Entire cohort $\mathrm{N}=274$} & \multicolumn{2}{|c|}{ Inappropriate $\mathrm{N}=133$} & \multicolumn{2}{|c|}{ Appropriate $\mathrm{N}=141$} & \multirow[t]{2}{*}{$P$ value } \\
\hline & Count & Percentage & Count & Percentage & Count & Percentage & \\
\hline \multicolumn{8}{|l|}{ Age } \\
\hline Median months (25th-75th percentile) & 22 & $(5-65)$ & 24 & $(5-79)$ & 22 & $(5-56)$ & 0.459 \\
\hline \multicolumn{8}{|l|}{ Gender } \\
\hline Male & 132 & $50.8 \%$ & 64 & $50 \%$ & 68 & $51.9 \%$ & 0.804 \\
\hline Female & 127 & $49.2 \%$ & 64 & $50 \%$ & 63 & $48.1 \%$ & \\
\hline \multicolumn{8}{|l|}{ Comorbidities } \\
\hline Neurologic/neuromuscular & 96 & $35.00 \%$ & 47 & $35.30 \%$ & 49 & $34.80 \%$ & 0.510 \\
\hline Pulmonary disease & 65 & $23.70 \%$ & 23 & $17.30 \%$ & 42 & $29.80 \%$ & 0.011 \\
\hline Gastrointestinal & 50 & $18.20 \%$ & 24 & $18.00 \%$ & 26 & $18.40 \%$ & 0.529 \\
\hline Metabolic diseases & 18 & $6.60 \%$ & 9 & $6.80 \%$ & 9 & $6.40 \%$ & 0.545 \\
\hline Endocrine disease & 11 & $4.00 \%$ & 8 & $6.00 \%$ & 3 & $2.10 \%$ & 0.091 \\
\hline Cardiac disease & 45 & $16.40 \%$ & 24 & $18.00 \%$ & 21 & $14.90 \%$ & 0.294 \\
\hline Renal disease & 27 & $9.90 \%$ & 15 & $11.30 \%$ & 12 & $8.50 \%$ & 0.286 \\
\hline Hematological disease & 9 & $3.30 \%$ & 3 & $2.30 \%$ & 6 & $4.30 \%$ & 0.280 \\
\hline Preterm & 31 & $11.30 \%$ & 13 & $9.80 \%$ & 18 & $12.80 \%$ & 0.278 \\
\hline Genetic/syndromic & 74 & $27.00 \%$ & 40 & $30.10 \%$ & 34 & $24.10 \%$ & 0.165 \\
\hline \multicolumn{8}{|l|}{ Admission type } \\
\hline Medical & 187 & $68.2 \%$ & 75 & $56.4 \%$ & 112 & $79.4 \%$ & $<0.001$ \\
\hline Surgical & 83 & $30.3 \%$ & 57 & $42.9 \%$ & 26 & $18.4 \%$ & $<0.001$ \\
\hline Trauma & 3 & $1.1 \%$ & 1 & $0.7 \%$ & 2 & $1.4 \%$ & 0.522 \\
\hline Burn & 1 & $0.4 \%$ & 0 & $0 \%$ & 1 & $0.8 \%$ & 0.485 \\
\hline \multicolumn{8}{|l|}{ Number of comorbidities } \\
\hline No comorbidities & 99 & $36.10 \%$ & 50 & $37.60 \%$ & 49 & $34.80 \%$ & 0.864 \\
\hline 1 to 2 & 130 & $47.40 \%$ & 61 & $45.90 \%$ & 69 & $48.90 \%$ & \\
\hline 3 or more & 45 & $16.40 \%$ & 22 & $16.50 \%$ & 23 & $16.30 \%$ & \\
\hline \multicolumn{8}{|l|}{ Type of antibiotic on initiation } \\
\hline Empiric & 187 & $68.2 \%$ & 77 & $57.9 \%$ & 110 & $78 \%$ & $<0.001$ \\
\hline Prophylactic & 61 & $22.3 \%$ & 45 & $33.8 \%$ & 16 & $11.3 \%$ & $<0.001$ \\
\hline Therapeutic/definitive & 26 & $9.5 \%$ & 11 & $8.3 \%$ & 15 & $10.6 \%$ & 0.323 \\
\hline \multicolumn{8}{|l|}{ Indication } \\
\hline Community acquired pneumonia & 53 & $19.3 \%$ & 13 & $9.8 \%$ & 40 & $28.4 \%$ & $<0.001$ \\
\hline Sepsis, hospital acquired & 29 & $10.6 \%$ & 13 & $9.8 \%$ & 16 & $11.3 \%$ & 0.411 \\
\hline Sepsis, community acquired & 27 & $9.9 \%$ & 13 & $10.5 \%$ & 13 & $9.2 \%$ & 0.436 \\
\hline Bronchiolitis & 26 & $9.5 \%$ & 14 & $10.5 \%$ & 12 & $8.5 \%$ & 0.358 \\
\hline CNS procedures e.g., EVD, VP shunt, tumor resection & 23 & $8.4 \%$ & 19 & $14.3 \%$ & 4 & $2.8 \%$ & 0.001 \\
\hline Other & 116 & $42.3 \%$ & 60 & $45.1 \%$ & 57 & $39.7 \%$ & 0.217 \\
\hline \multicolumn{8}{|l|}{ Documented indication in medical chart } \\
\hline Yes & 239 & $87.2 \%$ & 117 & $88 \%$ & 122 & $86.5 \%$ & 0.430 \\
\hline No & 35 & $12.8 \%$ & 16 & $12 \%$ & 19 & $13.5 \%$ & \\
\hline \multicolumn{8}{|l|}{ Appropriate cultures } \\
\hline Yes & 231 & $84.3 \%$ & 109 & $82 \%$ & 122 & $86.5 \%$ & 0.322 \\
\hline No & 43 & $15.7 \%$ & 24 & $18 \%$ & 19 & $13.5 \%$ & \\
\hline \multicolumn{8}{|l|}{ Decision at $72 \mathrm{~h}$ for empiric $(\mathrm{N}=187)$} \\
\hline Changed & 11 & $5.9 \%$ & 6 & $7.8 \%$ & 5 & $4.5 \%$ & 0.364 \\
\hline Continue with planned duration & 64 & $32.2 \%$ & 25 & $32.5 \%$ & 39 & $35.5 \%$ & 0.755 \\
\hline No action taken & 26 & $13.9 \%$ & 16 & $20.8 \%$ & 10 & $9.1 \%$ & 0.031 \\
\hline Discontinued & 86 & $46 \%$ & 30 & $39 \%$ & 56 & $50.9 \%$ & 0.136 \\
\hline Documented infection & & & & & & & \\
\hline
\end{tabular}


Table 2 (continued)

\begin{tabular}{|c|c|c|c|c|c|c|c|}
\hline \multirow[t]{2}{*}{ Variable } & \multicolumn{2}{|c|}{ Entire cohort $N=274$} & \multicolumn{2}{|c|}{ Inappropriate $\mathrm{N}=133$} & \multicolumn{2}{|c|}{ Appropriate $\mathrm{N}=141$} & \multirow[t]{2}{*}{$P$ value } \\
\hline & Count & Percentage & Count & Percentage & Count & Percentage & \\
\hline Yes & 60 & $21.9 \%$ & 29 & $21.8 \%$ & 31 & $22 \%$ & 1 \\
\hline No & 214 & $78.1 \%$ & 104 & $78.2 \%$ & 110 & $78 \%$ & \\
\hline \multicolumn{8}{|l|}{ MDRO } \\
\hline Yes & 25 & $41.7 \%$ & 9 & $30 \%$ & 16 & $53.3 \%$ & 0.115 \\
\hline No & 35 & $58.3 \%$ & 21 & $70 \%$ & 14 & $46.7 \%$ & \\
\hline $\begin{array}{l}\text { Duration of antibiotics course } \\
\text { Median days (25th-75th percentile) }\end{array}$ & 8 & $5-13$ & 10 & $6-14$ & 7 & $4-10$ & $<0.001$ \\
\hline
\end{tabular}

MDRO multi-drug resistant organisms

\section{Table 3 Inappropriate antibiotics classified by CDC 12-Step}

\begin{tabular}{llc}
\hline $\begin{array}{l}\text { Reason for non-adherence } \\
\text { to the CDC 12-step campaign }\end{array}$ & Number of courses & Percentage \\
\hline Step 6 & 48 & 36.1 \\
Step 4 & 23 & 17.3 \\
Step 10 & 21 & 15.8 \\
Step 9 & 6 & 4.5 \\
Steps 4 and 9 & 14 & 10.5 \\
Steps 4 and 10 & 11 & 8.3 \\
Steps 6 and 10 & 1 & 0.8 \\
Steps 4, 9, and 10 & 7 & 5.3 \\
Steps 4, 6 and 9 & 2 & 1.5 \\
Total & 133 courses \\
\hline
\end{tabular}

\section{Discussion}

The main objectives of this study were to describe antibiotic consumption in our setting, investigate appropriateness of antibiotic utilization by assessing adherence to the CDC's 12-steps and uncover factors associated with inappropriate antibiotic utilization. The findings suggest a high percentage of inappropriate antibiotics courses. The most common violated CDC steps were "target the pathogen" and "practice antimicrobial control". There was a higher percentage of inappropriate courses in surgical admissions and with prophylactic courses. Cefazolin and vancomycin had the highest number of inappropriate DOTs.

Total antibiotic consumption was 848.5 DOTs per 1000 patient days, indicating a rising increment from 708.3

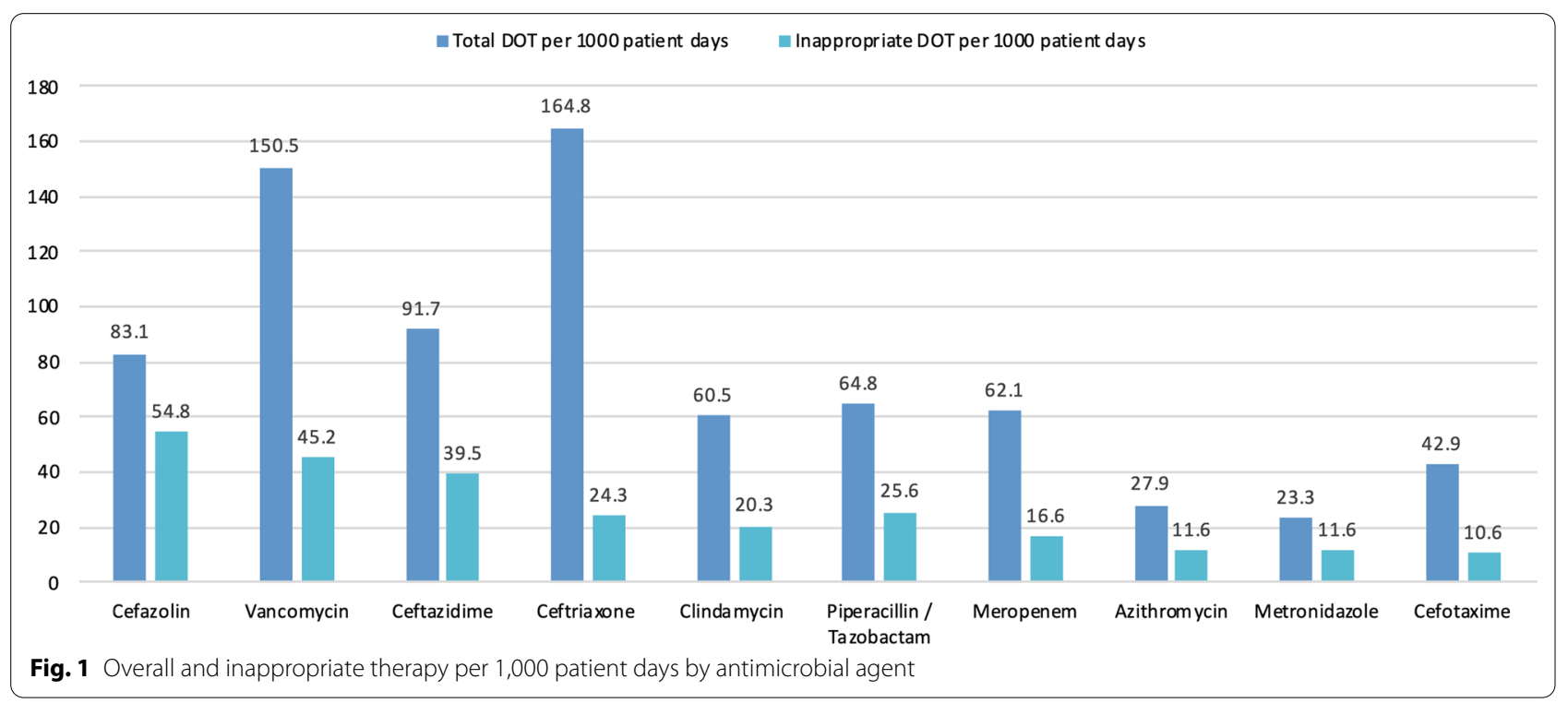


DOTs per 1000 patient-days previously reported between 2012 and 2015 [21]. This difference may be attributable in part, to seasonal variation and an increase in prescriptions during winter months in our study period [27]. Our study uncovered a high percentage of inappropriate antibiotic courses ( $n=133$ out of 274 courses, $48.5 \%$ ). Previous studies evaluating appropriateness of antibiotics have shown similar percentages in Turkey (50\%), Canada (16$60 \%)$, and Switzerland $(33 \%)[2,4,5]$.

The most common reason for non-adherence was violation of step 6 (target the pathogen) or step 4 (practice antimicrobial control). Nonadherence to step 4 includes inappropriate empiric or definitive antibiotic choices. Improving empirical and definitive choices would require a better understanding of common pathogens and local susceptibility patterns, and better utilization of diagnostics, in addition to reassessment and taking action after $72 \mathrm{~h}$ of antibiotic initiation. Within our cohort, for empiric antibiotics, a lack of action taken at $72 \mathrm{~h}$ was associated with a higher percentage of inappropriate antibiotic use $(\mathrm{P}=0.031)$. In view of this finding, conducting an antibiotic 'time-out' would be a suitable and effective intervention [26]. A time-out is an ASP intervention recommended by the CDC that standardizes the review of clinical and laboratory results at a predefined time post antibiotic initiation to identify opportunities for discontinuing or deescalating empiric antibiotics [28].

Nonadherence to step 6 suggests an inappropriate prophylactic choice or duration, inappropriate antibiotic combinations, or route of administration. In our cohort 45 out of 61 (74\%) prophylactic courses were deemed inappropriate. This may explain why the percentage of inappropriate antibiotics was higher in surgical patients $(\mathrm{P}<0.001)$. Unnecessary prolongation of prophylactic treatment for specific procedures or for the presence of drains may be a contributing factor. Guidelines for perioperative prophylaxis recommend durations not extending beyond $24 \mathrm{~h}$ from initiation irrespective of the surgical procedure or the presence of drains or catheters [22, 23].

It is noted that nonadherence to a combination of the CDC steps, and in particular combinations including steps 4,9 , and 10 have contributed to $30.7 \%$ of inappropriate DOTs. These steps are related to empiric and definitive antibiotic choices, durations, and avoiding the unnecessary use of broad spectrum agents. Antibiotic treatment decisions in intensive care are challenging and influenced by a difficulty to differentiate between bacterial and viral infections, a lack of gold standard to diagnose pneumonia and an uncertainty in sepsis etiology [29-32]; for instance, in our setting cultures were positive in only $38 \%$ of patients who met severe sepsis or septic shock criteria [33]. An international survey on antibiotics decision determinants found significant variability across countries, reflecting cultural and contextual factors [34]. The issue of nonadherence to multiple CDC steps found in the presented study and available literature emphasizes the need to support clinicians and PICU units with adequate diagnostics and local antibiotic guidelines to rationalize choices and durations of treatment.

Cefazolin and vancomycin contributed to one third of inappropriate antibiotic utilization (301 of 801 inappropriate DOTs, $36.6 \%)$. The finding that cefazolin had the highest inappropriate utilization supports the finding that CDC step 6 was the most violated step in nonadherent courses and that a higher percentage of inappropriate courses were seen in surgical patients, as it is the drug of choice for peri-operative prophylaxis. Inappropriate vancomycin utilization in our centre corresponds with studies in both adult and pediatric critical care settings $[35,36]$. Vancomycin prescription has been increasing in critical care settings, due to the risk of community and hospital acquired methicillin-resistant Staphylococcus aureus (MRSA) [37, 38]. Several strategies to control vancomycin use in critical care units have been proposed; negative MRSA surveillance swabs were found to have a high negative predictive value for subsequent MRSA infections [39]. Automating vancomycin prescriptions based on controlled approved indications and vancomycin targeted time-out were associated with reduction of inappropriate vancomycin utilization $[26,35]$.

This study has several limitations. First, data were collected retrospectively; thus, some information influencing decision making could have been missed. Second, this is a single center report, which limits its generalizability. Third, decisions regarding antibiotic appropriateness are prone to bias, despite assessing the appropriateness in this study by two independent infectious disease physicians based on the unified CDC 12 step classification. Additionally, due to the retrospective nature of the study, the accuracy of diagnoses was not confirmed, and the authors accepted all diagnoses made by treating physicians. This meant that we could not assess nonadherence to step 8 (treat infection but not contamination or colonization).

\section{Conclusions}

We were able to confirm a high prevalence of antibacterial utilization in the PICU with evidence of inappropriate prescription practices, mainly due to inappropriate perioperative prophylaxis durations and inappropriate empiric and definitive antibiotic choices. Based on our findings, the main areas for stewardship interventions include the development of empiric antibiotic guidelines (addresses step 4 and 9), re-education on surgical prophylaxis guidelines (addresses step 6), and the introduction of 'time-out' moments post-antibiotic initiation for empiric antibiotics 
(addresses step 10). Different approaches to antimicrobial stewardship need to be individualized based on identified concerns. Decisions regarding the appropriateness of antibiotic use could be facilitated by the development of local antibiotic guidelines and the utilization of tools such as the CDC steps to both standardize the process and limit bias and subjectivity.

\begin{abstract}
Abbreviations
PICU: Pediatric Intensive Care Unit; AMR: Antimicrobial resistance; WHO: World Health Organization; ICU: Intensive care unit; ASP: Antibiotic stewardship programs; KASCH: King Abdullah Specialized Children's Hospital; KAIMRC: King Abdullah International Medical Research Center; CDC: Centers for Disease Control and Prevention; DOT: Days of therapy; NICU: Neonatal intensive care unit; MRSA: Methicillin-resistant Staphylococcus aureus.
\end{abstract}

\section{Acknowledgements}

Not applicable.

\section{Authors' contributions}

YK, NA, HT, BA, and LA conceptualized and designed the study and designed the data collection instruments. HT, BA, and LA collected data. NA and NF coordinated and supervised data collection and carried out antibiotic appropriateness assessments. YK carried out the initial analyses and drafted the initial manuscript. YK, NA, and NF reviewed and revised the manuscript. All authors read and approved the final manuscript as submitted and agree to be accountable for all aspects of the work.

\section{Funding}

This study was funded by the King Abdullah International Medical Research Center (KAIRMC) (RC18/083/R). The source of funding was not involved in the study design; collection, analysis, and interpretation of data; and writing of the report.

\section{Availability of data and materials}

The datasets used and/or analyzed during the current study are available from the corresponding author on reasonable request.

\section{Ethics approval and consent to participate}

The study was approved by the King Abdullah International Medical Research Center (KAIRMC) Institutional Review Board (RC18/083/R).

\section{Consent for publication}

Not applicable.

\section{Competing interests}

The authors declare that they have no competing interests.

\section{Author details}

${ }^{1}$ Department of Pediatrics, Ministry of National Guards - Health Affairs, Riyadh, Kingdom of Saudi Arabia. ${ }^{2}$ College of Medicine, King Saud Bin Abdulaziz University for Health Sciences, Riyadh, Kingdom of Saudi Arabia. ${ }^{3}$ King Abdullah International Medical Research Center, Riyadh, Kingdom of Saudi Arabia.

Received: 20 March 2020 Accepted: 27 October 2020

Published online: 03 November 2020

\section{References}

1. Abbas Q, UI Haq A, Kumar R, Ali SA, Hussain K, Shakoor S. Evaluation of antibiotic use in Pediatric Intensive Care Unit of a developing country. Indian J Crit Care Med. 2016;20:291-4.

2. Blinova E, Lau E, Bitnun A, Cox P, Schwartz S, Atenafu E, et al. Point prevalence survey of antimicrobial utilization in the cardiac and pediatric critical care unit. Pediatr Crit Care Med. 2013;14:e280-8.
3. Brogan TV, Thurm C, Hersh AL, Gerber JS, Smith MJ, Shah SS, et al. Variability in antibiotic use across PICUs. Pediatr Crit Care Med. 2018;19:519-27.

4. Ceyhan M, Yildirim I, Ecevit C, Aydogan A, Ornek A, Salman N, et al. Inappropriate antimicrobial use in Turkish pediatric hospitals: a multicenter point prevalence survey. Int J Infect Dis. 2010;14:e55-61.

5. Fischer JE, Ramser M, Fanconi S. Use of antibiotics in pediatric intensive care and potential savings. Intensive Care Med. 2000;26:959-66.

6. Punchak M, Hall K, Seni A, Buck WC, DeUgarte DA, Hartford E, et al. Epidemiology of disease and mortality from a PICU in mozambique. Pediatr Crit Care Med. 2018;19:e603-10.

7. Weiss SL, Fitzgerald JC, Balamuth F, Alpern ER, Lavelle J, Chilutti M, et al. Delayed antimicrobial therapy increases mortality and organ dysfunction duration in pediatric sepsis. Crit Care Med. 2014;42:2409-17.

8. Weiss SL, Fitzgerald JC, Pappachan J, Wheeler D, Jaramillo-Bustamante JC, Salloo A, et al. Global epidemiology of pediatric severe sepsis: the sepsis prevalence, outcomes, and therapies study. Am J Respir Crit Care Med. 2015;191:1147-57.

9. Ergul AB, Gokcek I, Celik T, Torun YA. Assessment of inappropriate antibiotic use in pediatric patients: point-prevalence study. Turk Pediatri Ars. 2018;53:17-23.

10. Johnson MT, Reichley R, Hoppe-Bauer J, Dunne WM, Micek S, Kollef M. Impact of previous antibiotic therapy on outcome of Gram-negative severe sepsis. Crit Care Med. 2011;39:1859-65.

11. Rubio-Terres C, Garau J, Grau S, Martinez-Martinez L. Cast of Resistance Study g. Cost of bacteraemia caused by methicillin-resistant vs methicillin-susceptible Staphylococcus aureus in Spain: a retrospective cohort study. Clin Microbiol Infect. 2010;16:722-8.

12. Zilahi G, McMahon MA, Povoa P, Martin-Loeches I. Duration of antibiotic therapy in the intensive care unit. J Thorac Dis. 2016;8:3774-80.

13. O'Neill J. Review on antimicrobial resistance antimicrobial resistance: tackling a crisis for the health and wealth of nations. London: Review on Antimicrobial Resistance; 2014.

14. Howard P, Pulcini C, Levy Hara G, West RM, Gould IM, Harbarth S, et al. An international cross-sectional survey of antimicrobial stewardship programmes in hospitals. J Antimicrob Chemother. 2015;70:1245-55.

15. World Health Organization A. Draft global action plan for antimicrobial resistance. https://apps.who.int/gb/ebwha/pdf_files/EB136/B136_20-en. pdf. Accessed 15 Oct 2019.

16. Al Johani SM, Akhter J, Balkhy H, El-Saed A, Younan M, Memish Z. Prevalence of antimicrobial resistance among gram-negative isolates in an adult intensive care unit at a tertiary care center in Saudi Arabia. Ann Saudi Med. 2010;30:364-9.

17. Alqasim E, Aljohani S, Alshamrani M, Daneman N, Fowler R, Arabi Y. Duration of antibiotic therapy for critically ill patients with bloodstream infections: a retrospective observational in Saudi Arabia. Ann Thorac Med. 2018:13:63-5.

18. Zowawi HM. Antimicrobial resistance in Saudi Arabia. An urgent call for an immediate action. Saudi Med J. 2016;37:935-40.

19. Barlam TF, Cosgrove SE, Abbo LM, MacDougall C, Schuetz AN, Septimus EJ, et al. Implementing an antibiotic stewardship program: guidelines by the infectious diseases society of America and the Society for Healthcare Epidemiology of America. Clin Infect Dis. 2016;62:e51-77.

20. Dellit TH, Owens RC, McGowan JE Jr, Gerding DN, Weinstein RA, Burke JP, et al. Infectious Diseases Society of America and the Society for Healthcare Epidemiology of America guidelines for developing an institutional program to enhance antimicrobial stewardship. Clin Infect Dis. 2007:44:159-77.

21. Balkhy HH, El-Saed A, AlShehri A, Alshaalan M, Hijazi O, El-Metwally A, et al. Antimicrobial consumption in three pediatric and neonatal intensive care units in Saudi Arabia: 33-month surveillance study. Ann Clin Microbiol Antimicrob. 2019;18:20

22. Bratzler DW, Dellinger EP, Olsen KM, Perl TM, Auwaerter PG, Bolon MK, et al. Clinical practice guidelines for antimicrobial prophylaxis in surgery. Am J Health Syst Pharm. 2013;70:195-283.

23. South Australian Expert Advisory Group on antimicrobial resistance. Surgical antimicrobial prophylaxis clinical guideline. 2017. https://www. sahealth.sa.gov.au/wps/wcm/connect/6bb523804358edbd883b9ef2c adc00ab/Surgical\%2BAntimicrobial\%2BProphylaxis_v2.0+July+2020. pdf?MOD=AJPERES\&amp;CACHEID=ROOTWORKSPACE-6bb5238043 58edbd883b9ef2cadc00ab-niPZ5oi. Accessed 15 Oct 2019 
24. Patel SJ, Oshodi A, Prasad P, Delamora P, Larson E, Zaoutis T, et al. Antibiotic use in neonatal intensive care units and adherence with Centers for Disease Control and Prevention 12 Step Campaign to Prevent Antimicrobial Resistance. Pediatr Infect Dis J. 2009;28:1047-51.

25. Stanic Benic M, Milanic R, Monnier AA, Gyssens IC, Adriaenssens N, Versporten A, et al. Metrics for quantifying antibiotic use in the hospital setting: results from a systematic review and international multidisciplinary consensus procedure. J Antimicrob Chemother. 2018;73:vi50-8.

26. Adams SM, Ngo L, Morphew T, Babbitt CJ. Does an antimicrobial time-out impact the duration of therapy of antimicrobials in the PICU? Pediatr Crit Care Med. 2019;20:560-7.

27. Holstiege J, Schink T, Molokhia M, Mazzaglia G, Innocenti F, Oteri A, et al. Systemic antibiotic prescribing to paediatric outpatients in 5 European countries: a population-based cohort study. BMC Pediatr. 2014;14:174.

28. Pollack LA, Srinivasan A. Core elements of hospital antibiotic stewardship programs from the Centers for Disease Control and Prevention. Clin Infect Dis. 2014;59(Suppl 3):S97-100

29. Lynch T, Bialy L, Kellner JD, Osmond MH, Klassen TP, Durec T, et al. A systematic review on the diagnosis of pediatric bacterial pneumonia: when gold is bronze. PLoS ONE. 2010;5:e11989.

30. Simoes EAF, Cherian T, Chow J, Shahid-Salles SA, Laxminarayan R, John TJ, et al. Acute respiratory infections in children. In: Jamison DT, Breman JG, Measham AR, Alleyne G, Claeson M, et al., editors. Disease control priorities in developing countries. Washington: The World Bank; 2006.

31. Bobillo-Perez S, Rodriguez-Fanjul J, Jordan Gl. Is Procalcitonin useful in pediatric critical care patients? Biomark Insights. 2018:13:1177271918792244

32. Joynes E. More challenges around sepsis: definitions and diagnosis. J Thorac Dis. 2016:8:E1467-9.
33. Alsadoon A, Alhamwah M, Alomar B, Alsubaiel S, Almutairi AF, Vishwakarma RK, et al. Association of antibiotics administration timing with mortality in children with sepsis in a tertiary care hospital of a developing country. Front Pediatr. 2020;8:566

34. Noel KC, Papenburg J, Lacroix J, Quach C, O'Donnell S, Gonzales M, et al. International survey on determinants of antibiotic duration and discontinuation in pediatric critically ill patients. Pediatr Crit Care Med. 2020;21:e696-706.

35. Di Pentima MC, Chan S. Impact of antimicrobial stewardship program on vancomycin use in a pediatric teaching hospital. Pediatr Infect Dis J. 2010;29:707-11.

36. Mahmoodian A, Abbasi S, Farsaei S. A new approach to Vancomycin utilization evaluation: a cross-sectional study in intensive care unit. J Res Pharm Pract. 2016:5:279-84.

37. Milstone AM, Carroll KC, Ross T, Shangraw KA, Perl TM. Communityassociated methicillin-resistant Staphylococcus aureus strains in pediatric intensive care unit. Emerg Infect Dis. 2010;16:647-55.

38. Qadri I, Malik I, Ahmed K. Staphylococcus aureus infection in a pediatric ICU: a hospital based prospective observational study. Indian J Crit Care Med. 2019:23:210-2.

39. Chotiprasitsakul D, Tamma PD, Gadala A, Cosgrove SE. The role of negative methicillin-resistant Staphylococcus aureus nasal surveillance swabs in predicting the need for empiric vancomycin therapy in intensive care unit patients. Infect Control Hosp Epidemiol. 2018;39:290-6.

\section{Publisher's Note}

Springer Nature remains neutral with regard to jurisdictional claims in published maps and institutional affiliations.
Ready to submit your research? Choose BMC and benefit from:

- fast, convenient online submission

- thorough peer review by experienced researchers in your field

- rapid publication on acceptance

- support for research data, including large and complex data types

- gold Open Access which fosters wider collaboration and increased citations

- maximum visibility for your research: over $100 \mathrm{M}$ website views per year

At BMC, research is always in progress.

Learn more biomedcentral.com/submissions 